\title{
Construction of Ang2-siRNA chitosan magnetic nanoparticles and the effect on Ang2 gene expression in human malignant melanoma cells
}

\author{
ZHAO-LIANG LIU ${ }^{1}$, CAI-LIAN YOU ${ }^{1}$, BIAO WANG ${ }^{1}$, JIAN-HONG LIN ${ }^{1}$, XUE-FENG HU ${ }^{2}$, \\ XIU-YING SHAN ${ }^{1}$, MEI-SHUI WANG ${ }^{1}$, HOU-BING ZHENG ${ }^{1}$ and YAN-DING ZHANG ${ }^{2}$ \\ ${ }^{1}$ Department of Plastic Surgery, The First Affiliated Hospital of Fujian Medical University, Fuzhou, Fujian 350005; \\ ${ }^{2}$ College of Life Sciences, Fujian Normal University, Fuzhou, Fujian 350108, P.R. China
}

Received January 20, 2015; Accepted March 1, 2016

DOI: $10.3892 / \mathrm{ol} .2016 .4539$

\begin{abstract}
The aim of the present study was to construct angiopoietin-2 (Ang2)-small interfering (si)RNA chitosan magnetic nanoparticles and to observe the interference effects of the nanoparticles on the expression of the Ang2 gene in human malignant melanoma cells. Ang2-siRNA chitosan magnetic nanoparticles were constructed and transfected into human malignant melanoma cells in vitro. Red fluorescent protein expression was observed, and the transfection efficiency was analyzed. Reverse transcription-quantitative polymerase chain reaction (RT-qPCR) was used to assess the inhibition efficiency of Ang2 gene expression. Ang2-siRNA chitosan magnetic nanoparticles were successfully constructed, and at a mass ratio of plasmid to magnetic chitosan nanoparticles of 1:100, the transfection efficiency into human malignant melanoma cells was the highest of the ratios assessed, reaching $61.17 \%$. RT-qPCR analysis showed that the magnetic chitosan nanoparticles effectively inhibited Ang2 gene expression in cells, and the inhibition efficiency reached 59.56\% ( $\mathrm{P}<0.05)$. Ang2-siRNA chitosan magnetic nanoparticles were successfully constructed. The in vitro studies showed that the nanoparticles inhibited Ang2 gene expression in human malignant melanoma tumor cells, which laid the foundation and provided experimental evidence for additional future in vivo studies of intervention targeting malignant melanoma tumor growth in nude mice.
\end{abstract}

\section{Introduction}

The overall incidence of cancer is continually increasing, with an average annual incidence rate of 3-5\% (1). Melanoma is a human malignancy characterized by invasion and metastasis,

Correspondence to: Professor Biao Wang, Department of Plastic Surgery, The First Affiliated Hospital of Fujian Medical University, 20 Chazhong Road, Fuzhou, Fujian 350005, P.R. China

E-mail: docbiaowang@163.com

Key words: RNA interference, angiopoietin 2, chitosan magnetic nanoparticles, malignant melanoma in which the cells are malignantly transformed from melanocytes. As the melanoma demonstrates rapid progression, the prognosis is poor. There is no effective treatment for melanoma at present, with no progress made over the last 13 years $(2,3)$. The angiopoietin (Ang)-endothelial-specific receptor tyrosine kinase 2 (Tie2) system is widely expressed in human tumor vasculature remodeling, but no notable expression occurs in normal tissues, which results in the Ang-Tie2 system being an attractive potential target for anti-angiogenic cancer therapy (4). Ang is expressed at a high level in malignant melanoma cells compared with normal tissues (5). Thus, it is possible to inhibit angiogenesis by blocking Ang expression and to inhibit the growth of malignant melanoma, therefore achieving a therapy for malignant melanoma (6).

Preliminary findings indicated that RNA interference (RNAi) technology may silence Ang2 gene expression, thereby inhibiting malignant melanoma xenograft angiogenesis and tumor growth (7-11). However, in the preliminary studies $(8,10)$, a local intratumoral injection was used, which is not suitable for routine clinical use, but the intravenous injection of lentiviral vectors has safety and efficacy issues that affected the feasibility and significance of its use in additional studies. Based on the large specific surface area of nanoscale genic carriers compared with vector, target cell surface ligand or antibody can be coupled on the surface of nanomaterials. Certain nanomaterials, including magnetic nanomaterials, such as magnetic metal nanowire, magnetic nanofilms and nanocrystalline soft magnetic materials, demonstrated magnetic compliance, and may be directed to move in the magnetic field to obtain the characteristics of active targeting. Active targeting vectors demonstrate markedly improved specific gene delivery and enhance the uptake of the target gene to the target cells.

The present study was based on previous studies (7-11) and combined nano-biotechnology with RNAi technology, with the preparation of Ang2-small interfering (si)RNA magnetic chitosan nanoparticles, which were used to transfect human malignant melanoma cells. The measurement of the efficiency of the inhibition of Ang2 gene expression provided a hypothetical basis and experimental evidence for the safety of studying Ang2 in animals in vivo, as well as inhibition experiments of tumor growth in nude mice. 


\section{Materials and methods}

Primer synthesis. Primers were synthesized by Takara (Dalian, China), as follows: Ang2 upstream, 5'-GGGCATAAT TGTGCTTGACTGG-3' and downstream, 5'-ATGGTCTTT AGAATTGGGTCACTGG-3'; glyceraldehyde-3-phosphate dehydrogenase (GAPDH) upstream, 5'-GCACCGTCAAGG CTGAGAAC-3' and downstream, 5'-TGGTGAAGACGC CAGTGGA-3'. The Ang2 fragment was 183 bp long and the GAPDH fragment was 138 bp long.

Preparation of magnetic chitosan nanoparticles. In total, $0.15 \mathrm{~g} \mathrm{Fe}_{3} \mathrm{O}_{4}$ magnetic nanoparticles (Nanjing Emperor Nano Materials Co., Ltd., Nanjing, China) were dispersed in $20 \mathrm{ml} 1.5 \%$ chitosan solution (relative molec-

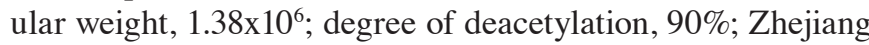
Aoxing Biotechnology Co., Ltd., Kanmen, Zhejiang, China) subsequent to ultrasonic dispersal (JY98-IIIDN; Shanghai Shengke Instrument \& Equipment Co., Ltd., Shanghai, China) and stirring. Subsequently, $80 \mathrm{ml}$ liquid paraffin (Nujol; Hangzhou Yongxin Hardware Co., Ltd., Hangzhou, China) and petroleum ether mixture (Jining Huakai Resin Co., Ltd, Jining, China) containing $2 \mathrm{ml}$ Span-80 (Jiangsu Haian Petrochemical Plant, Nantong, China) was added to $20 \mathrm{ml} 1.5 \%$ chitosan solution. The volume ratio of Nujol (Hangzhou Yongxing Hardware \& Electrical Appliance Co. Ltd., Hangzhou, China) to petroleum ether was 7:5. An emulsion was obtained by stirring at $40^{\circ} \mathrm{C}$ for $30 \mathrm{~min}$ using a MYP2011-100 electric mixer (Shanghai Mei Yingpu Instrument Manufacturing Co., Ltd.,

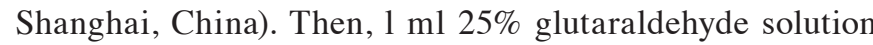
(Hubei Xinjing New Material Co., Ltd., Wuhan, China) was diluted to $10 \mathrm{ml}$, and the glutaraldehyde solution was slowly added dropwise prior to incubation in a water bath at $40^{\circ} \mathrm{C}$ for $30 \mathrm{~min}$. The $\mathrm{pH}$ of the glutaraldehyde solution was adjusted with $1 \mathrm{~mol} / \mathrm{l} \mathrm{NaOH}$ solution (Fuzhou Xinrong Chemical Co., Ltd., Fuzhou, China) to pH 9.0. The solution was then heated to $60^{\circ} \mathrm{C}$ and reacted at a constant temperature for $1 \mathrm{~h}$. Finally, the solution was thoroughly washed with ether (99.7\%), acetone (99.7\%), anhydrous ethanol (99\%) and distilled water (Fuzhou Xinrong Chemical Co., Ltd.) in succession to obtain magnetic chitosan nanoparticles.

Transmission electron microscopy (TEM) of magnetic nanoparticles of chitosan. A $1 \mathrm{mg}$ sample of magnetic chitosan nanoparticles (Wujiang Hongli Chemical Co., Ltd., Suzhou, China) was added to a $10 \mathrm{ml}$ glass bottle with $2 \mathrm{ml}$ dispersant (0.5\% sodium hexametaphosphate; Wujiang Hongli Chemical Co., Ltd.). The solution was ultrasonically dispersed using a JY98-IIIDN ultrasonic cell disruptor (Shanghai Shengke Instrument \& Equipment Co., Ltd.) for $6 \mathrm{sec}$. The sample was placed on a copper grid within $2 \mathrm{~min}$. The size and morphology of the superparamagnetic particles chitosan nanoparticles was directly observed by TEM using the JEM-2000EX transmission electron microscope manufactured by JEOL USA, Inc. (Peabody, MA, USA).

Sediment assays. For the sediment assays, 6 groups of $10 \mathrm{mg}$ chitosan magnetic nanoparticles were weighed, and each was dissolved in $20 \mathrm{ml}$ phosphate-buffered saline (PBS; pH 6.5; Yocon Biotechnology Co., Ltd., Beijing, China). Ultrasonic oscillation (200 W; 3 min) was then performed. Subsequently, 3 groups of chitosan magnetic nanoparticles $(10 \mathrm{mg})$ were treated by a magnetic field acting on the base of the container for 5, 10 or $20 \mathrm{~min}$. The remaining 3 groups were incubated at room temperature for 5, 10 or $20 \mathrm{~min}$. Images were captured, and the size and morphology of the chitosan magnetic nanoparticles observed using a JEM-2000EX transmission electron microscope manufactured by JEOL USA, Inc.

Ang2-siRNA vector combined with chitosan magnetic nanoparticles. In total, $1 \mathrm{mg}$ chitosan magnetic nanoparticles were weighed and added to $1 \mathrm{ml}$ PBS ( $\mathrm{pH}$ 7.4). Ultrasonic oscillation ( $200 \mathrm{~W}$; $3 \mathrm{~min}$ ) was then performed. Subsequently, $2 \mathrm{ml}$ polylysine (Zhengzhou Bainafo Bioengineering Co., Ltd., Zhengzhou, China), which was diluted with PBS to a concentration of $0.1 \mathrm{mg} / \mathrm{ml}$, was added to the nanoparticles and mixed thoroughly, prior to incubation at room temperature for $10 \mathrm{~min}$. The Ang2-siRNA plasmid contained two RNAi sequences, as follows: S1, 5'-ACCCCACTGTTGCTAAAGATTCAAGAG ATCTTTAGCAACAGTGGGGTTTTTT-3'; and S2, 5'-GCC ACGGTGAATAATTCAGTTCTCGAGAACTGAATTATT CACCGTGGCTTTTT-3' (Wuhan Xima Biological Technology Co., Ltd., Wuhan, China). This plasmid and the polylysine-modified magnetic nanoparticles of chitosan were mixed at mass ratios of 1:1, 1:10, 1:100 and 1:1,000, and were then incubated at room temperature for $1 \mathrm{~h}$.

Transfection. The human malignant melanoma A-375 cells were purchased from Shanghai Institutes for Biological Sciences, Chinese Academy of Sciences (Shanghai, China). Cells $\left(2-4 \times 10^{5}\right)$ were seeded with Dulbecco's modified Eagle's medium (DMEM) containing 10\% fetal bovine serum (HyClone; GE Healthcare Life Sciences, Logan, UT, USA) in 6-well plates at $37^{\circ} \mathrm{C}$ and $5 \% \mathrm{CO}_{2}$ until the logarithmic growth phase was reached, and $2 \mathrm{~h}$ prior to transfection, serum-free medium was used instead. The cells were transfected with $4 \mu \mathrm{g}$ DNA per well, using serum-free DMEM (HyClone; GE Healthcare Life Sciences) as the cell medium. The Ang2-siRNA plasmid and magnetic chitosan nanoparticles were combined into Ang2-siRNA magnetic chitosan nanoparticles at a mass ratio of 1:1, 1:10, 1:100 or 1:1,000, and added to three 6-well cell culture plates with diameter of $35 \mathrm{~mm}$ and cultured at $37^{\circ} \mathrm{C}$ in a $5 \% \mathrm{CO}_{2}$ incubator (YCP-200; Changsha Hua Xi Electronics Technetronic Co., Ltd., Changsha, China) for $12 \mathrm{~h}$. The cells were aspirated and the original medium was then discarded. DMEM containing $10 \%$ fetal bovine serum was added to the cells, and the cells were cultured for $48 \mathrm{~h}$. Subsequent to culture, red fluorescent protein was observed under an Olympus CKX41 fluorescence microscope (On Haipu He Optoelectronics Technology Co., Ltd., Shanghai, China) to assess protein expression/transfection, and images were captured and recorded. The Ang2-siRNA magnetic chitosan nanoparticle group with the highest transfection efficiency was classified as the experimental group. The group transfected with empty vector magnetic chitosan nanoparticles with the same mass was classified as the control group.

For the negative control, empty vector magnetic chitosan nanoparticles with the same mass (mass ratio, 1:1, 1:10, 1:100 or $1: 1,000$ ) were added to three 6 -well cell culture plates with a diameter of $35 \mathrm{~mm}$ and cultured in a $5 \% \mathrm{CO}_{2}$ incubator at $37^{\circ} \mathrm{C}$ 
for $12 \mathrm{~h}$. Following incubation, the cells were aspirated and the original culture medium was discarded. DMEM containing $10 \%$ fetal bovine serum, and cultured in a $5 \% \mathrm{CO}_{2}$ incubator at $37^{\circ} \mathrm{C}$ for $48 \mathrm{~h}$. Subsequent to incubation, red fluorescent was observed under a fluorescence microscope (Olympus CKX41; On Haipu He Optoelectronics Technology Co., Ltd.) to assess protein expression/transfection, and images were captured and recorded. The cells were digested with trypsin (Shanghai Biological Technology Co., Ltd. Shanghai, China), and an inverted fluorescence microscope was used to count the red fluorescence cells under ordinary and mercury light sources. The cell count results obtained using a hemocytometer (XB-K-25; Shanghai Daming Laboratory Instrument Co., Ltd, Shanghai, China) were used to calculate the transfection efficiency.

Reverse transcription-quantitative polymerase chain reaction $(R T-q P C R)$. In total, $10^{6}$ cells were extracted from the experimental and control groups and total RNA was extracted using the TRIzol method. Reverse transcription was performed to obtain complementary (c)DNA using PrimeScript RT Reagent kit (Takara), according to the manufacturer's protocol. Based on the corresponding quantification cycle $(\mathrm{Cq})$ value generated by the SYBR Premix Ex Taq kit (Takara), the PCR system was performed as follows: 45 cycles of $95^{\circ} \mathrm{C}$ for $5 \mathrm{sec}, 60^{\circ} \mathrm{C}$ for $34 \mathrm{sec}$ and $95^{\circ} \mathrm{C}$ for $15 \mathrm{sec}$. For the $\mathrm{Cq}$ value, the fluorescent signal in each reaction tube should reach the set threshold number of cycles. The formula $\Delta \Delta \mathrm{Ct}=\Delta \mathrm{Ct} 1-\Delta \mathrm{Ct} 2$ was used to calculate Ang2 inhibition, and the formula N1 / N2 $=2^{-\Delta \Delta C}$ was used to calculate the expression efficiency of RNAi for inhibiting Ang2, where N1 indicates Ang2 expression of the experimental group and N2 indicates Ang2 expression of the control group.

Statistical analysis. Statistical analysis was performed using the Statistical Package for Social Sciences, version 13.0 (SPSS, Inc., Chicago, IL, USA). Data was compared using the independent two-sample t-test. $\mathrm{P}<0.05$ was considered to indicate a statistically significant difference.

\section{Results}

Visual observation of chitosan magnetic nanoparticles. Chitosan magnetic nanoparticles may be well dispersed in distilled water to yield a dark brown suspension (Fig. 1A) with a good magnetic response (Fig. 1B).

TEM of magnetic chitosan nanoparticles. Under TEM, the majority of magnetic chitosan nanoparticles were oval and round, with a small number demonstrating an irregular shape. The boundaries of the nanoparticles were clear. The central portion of the particles was a darker color and the surroundings were shallow, suggesting the existence of a shell core structure (Fig. 2).

Sediment assays. Subsequent to agitation, the magnetic chitosan nanoparticles were well dispersed in distilled water (Figs. 3A-C and 4A-C), but the nanoparticles may precipitate to the bottom of the container due to gravity. The supernatant obtained by standing at room temperature for $10 \mathrm{~min}$ (Fig. 3E)
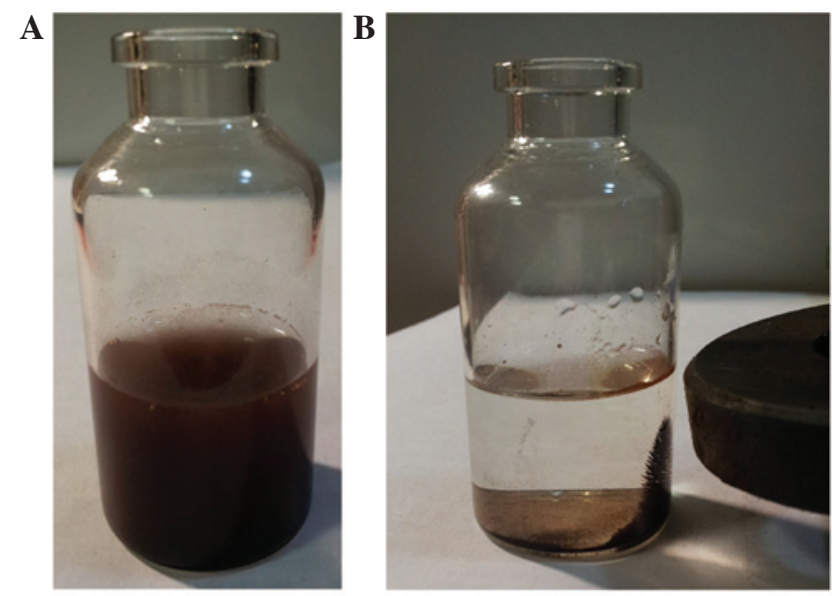

Figure 1. Solution of chitosan magnetic nanoparticles. Chitosan magnetic nanoparticles were dispersed in (A) distilled water with (B) a good magnetic response.

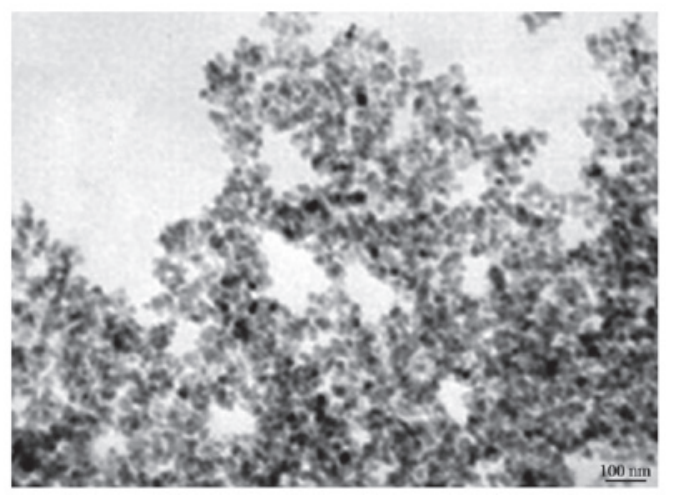

Figure 2. Chitosan magnetic nanoparticles observed by transmission electron microscopy. Magnfication, x50,000.

was clearer compared with the supernatant obtained by standing for $5 \mathrm{~min}$ (Fig. 3D), while the supernatant obtained subsequent to $20 \mathrm{~min}$ (Fig. 3F) was similar to that obtained at $10 \mathrm{~min}$. The supernatant solutions subsequent to $5 \mathrm{~min}$ (Fig. 4D), $10 \mathrm{~min}$ (Fig. 4E) and $20 \mathrm{~min}$ (Fig. 4F) in the magnetic field were similar. Due to the good response and superparamagnetic properties, the magnetic nanoparticles may reach the location of the tumor in the guidance of the magnetic field, which created the conditions for magnetic targeting drug experiments.

Determination of the appropriate mass ratio. Malignant melanoma is a highly malignant tumor with fast growth. The cells are loose, polygonal and adherent under normal conditions (Fig. 5A). Prior to the transfection assays, the malignant melanoma cells were cultured, and transfection was conducted when the malignant melanoma cells grew to $\sim 75 \%$ confluency (Fig. 5B).

The Ang2-siRNA vector (Fig. 6) and chitosan magnetic nanoparticles at a mass ratio of 1:1, 1:10, 1:100 or 1:1,000 were transfected into human malignant melanoma cells, and the cells were then observed under a fluorescent microscope (Olympus CKX41; On Haipu He Optoelectronics Technology Co., Ltd.) and images were captured (Fig. 7A-D). When the mass ratio was 1:100, the emitted red fluorescence was the 
Table I. Efficiency of angiopoietin-2-small interfering RNA plasmid chitosan magnetic nanoparticle transfection into human malignant melanoma cells.

Total number of red fluorescent cells, $\mathrm{n}$

\begin{tabular}{lccr}
\cline { 2 - 3 } Mass ratio & Under mercury light & Under ordinary light & $\begin{array}{c}\text { Transfection } \\
\text { efficiency, } \%\end{array}$ \\
\hline $1: 1$ & 0 & 118 & 0.00 \\
$1: 10$ & 10 & 107 & 9.35 \\
$1: 100$ & 63 & 103 & 61.17 \\
$1: 1,000$ & 35 & 84 & 41.67
\end{tabular}

All cells were visualized using a hemocytometer.

Table II. Efficiency of the inhibition of angiopoietin-2 expression by RNA interference.

\begin{tabular}{lccc}
\hline Group $(\mathrm{n}=3)$ & Average $\Delta \mathrm{Cq}$ values & $\Delta \Delta \mathrm{Cq}$ & Expression efficiency $(\%)$ \\
\hline Control $(\mathrm{Cq})$ & $9.389+0.223$ & & 59.56 \\
Experimental $(\mathrm{Cq})$ & $10.695+0.329^{\mathrm{a}}$ & 1.306 & 59 \\
\hline
\end{tabular}

${ }^{\text {a }}<0.05$ vs. experimental group and control group. $\mathrm{Cq}$, quantification cycle.
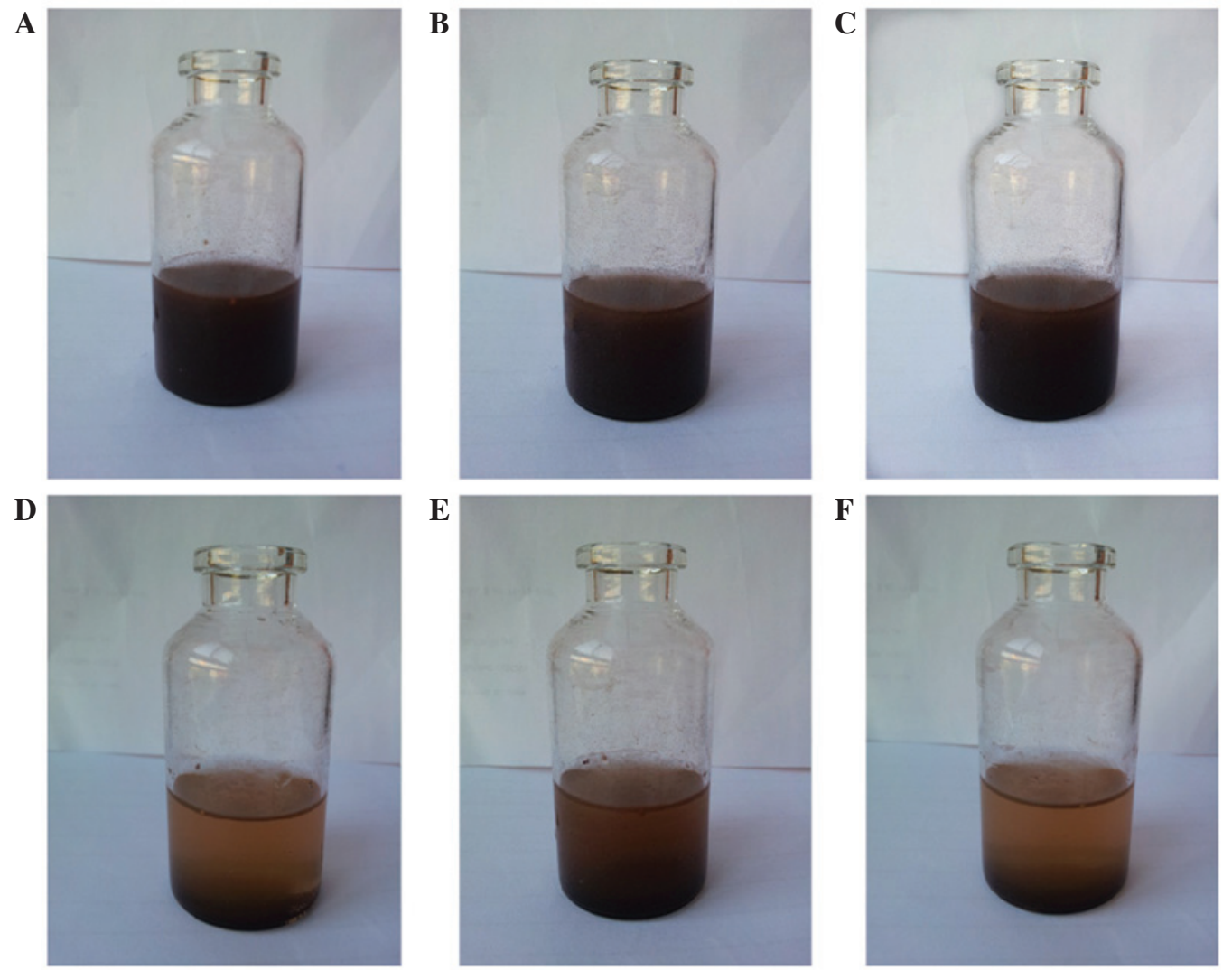

Figure 3. Standing solution obtained at different times at room temperature. (A-C) Mixing solution of chitosan magnetic nanoparticles. Solution subsequent to standing at room temperature for (D) $5 \mathrm{~min}$, (E) $10 \mathrm{~min}$ and (F) $20 \mathrm{~min}$.

strongest (Fig. 7C). The cells in each group were digested into single cell suspensions and counted using a hemocytometer (Table I), and the appropriate mass ratio was determined to be 1:100 for subsequent experiments.
Efficiency of RNAi inhibition of Ang2 expression. Total RNA was extracted from malignant melanoma cells in the experimental group and the control group. The RNA was reverse transcribed into cDNA, and RT-qPCR was performed using 
A

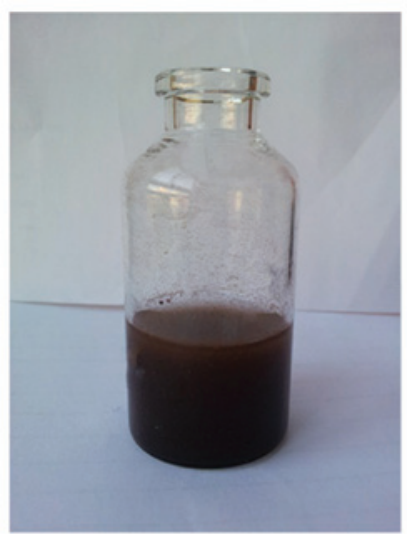

$\mathbf{D}$

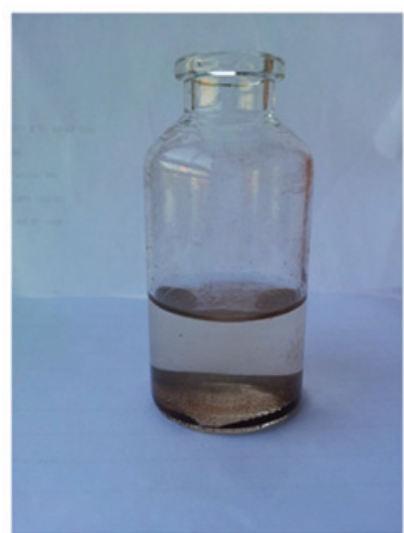

B

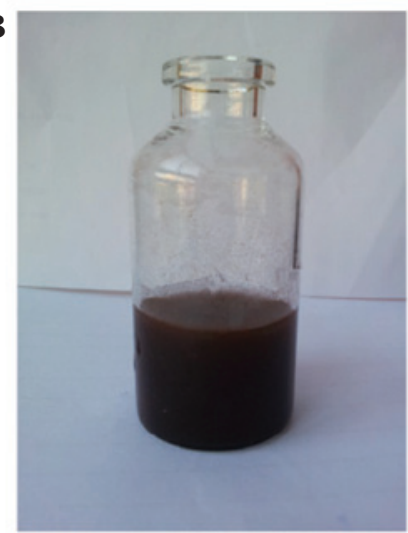

$\mathbf{E}$

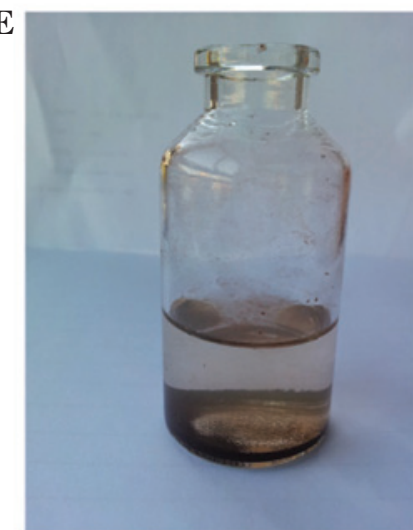

C

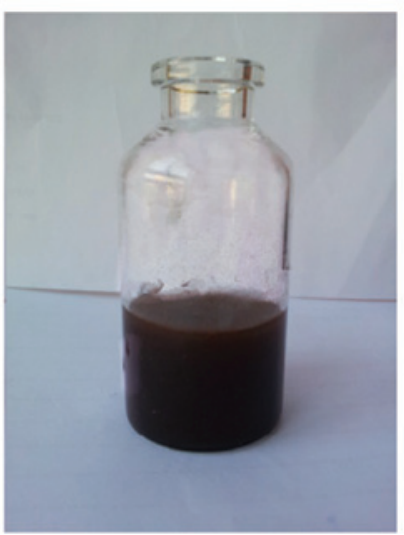

F

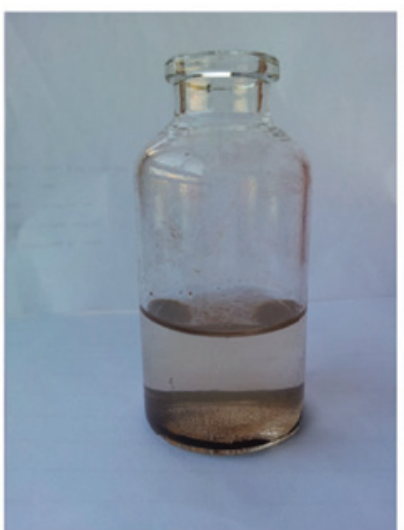

Figure 4. Standing solution obtained at different times under a magnetic field. (A-C) Mixing solution of chitosan magnetic nanoparticles. Solution subsequent to standing under a magnetic field for (D) $5 \mathrm{~min}$, (E) $10 \mathrm{~min}$ and (F) $20 \mathrm{~min}$.

A

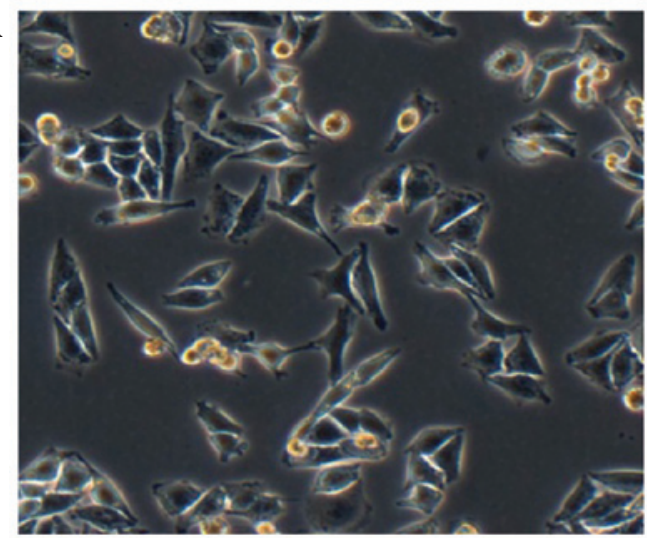

$\mathbf{B}$

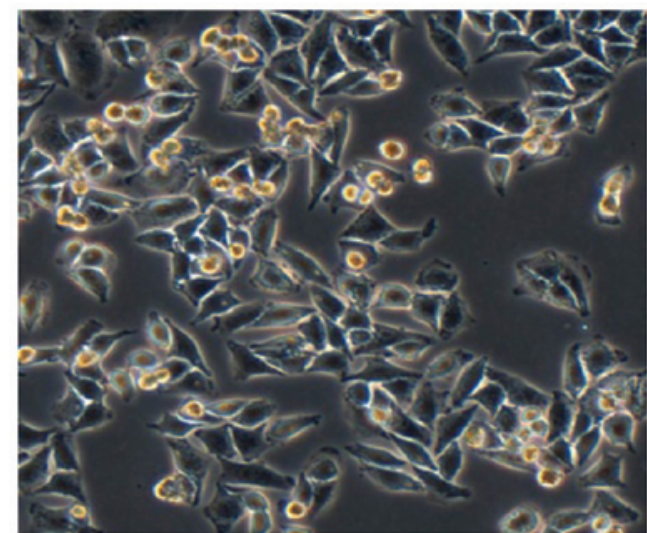

Figure 5. Malignant melanoma cells. (A) Normal adherent malignant melanoma cells. (B) Normal adherent malignant melanoma cells grew to cover $75 \%$ of the full plate.

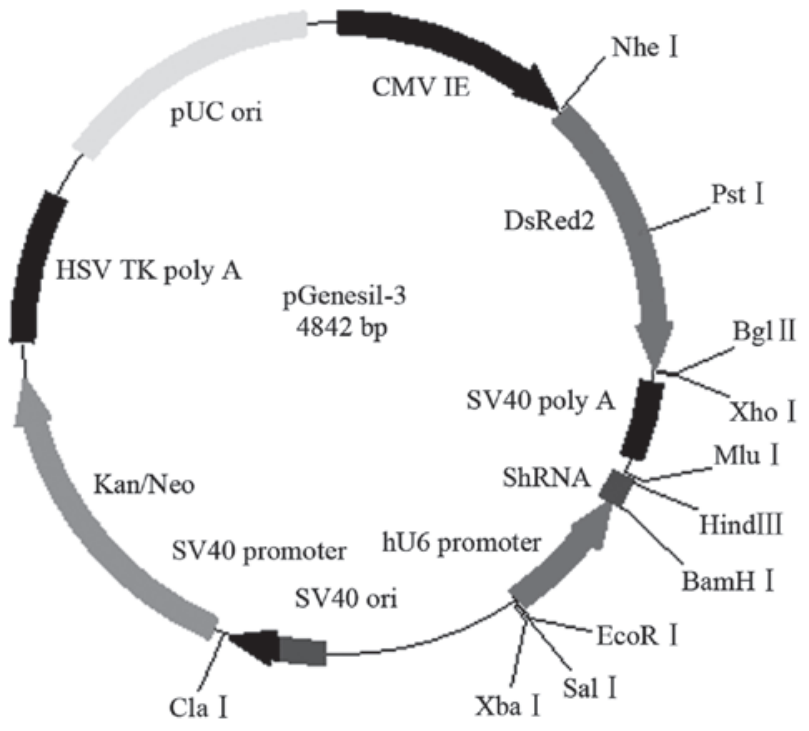

Figure 6. pGenesil-3 recombinant plasmid. The angiopoietin-2-small interfering RNA plasmid is shown.

an equal amount of GAPDH cDNA to obtain the Cq value. The differences in the $\mathrm{Cq}$ value between the groups ranged between 0.01 and 0.1 (data not shown). First, RNA purity of the two samples was determined to be good. Second, the cDNA template of the two samples participating the reactions was extremely similar. An equal amount of the cDNA template was used for the two samples in the Ang2 gene RT-qPCR 

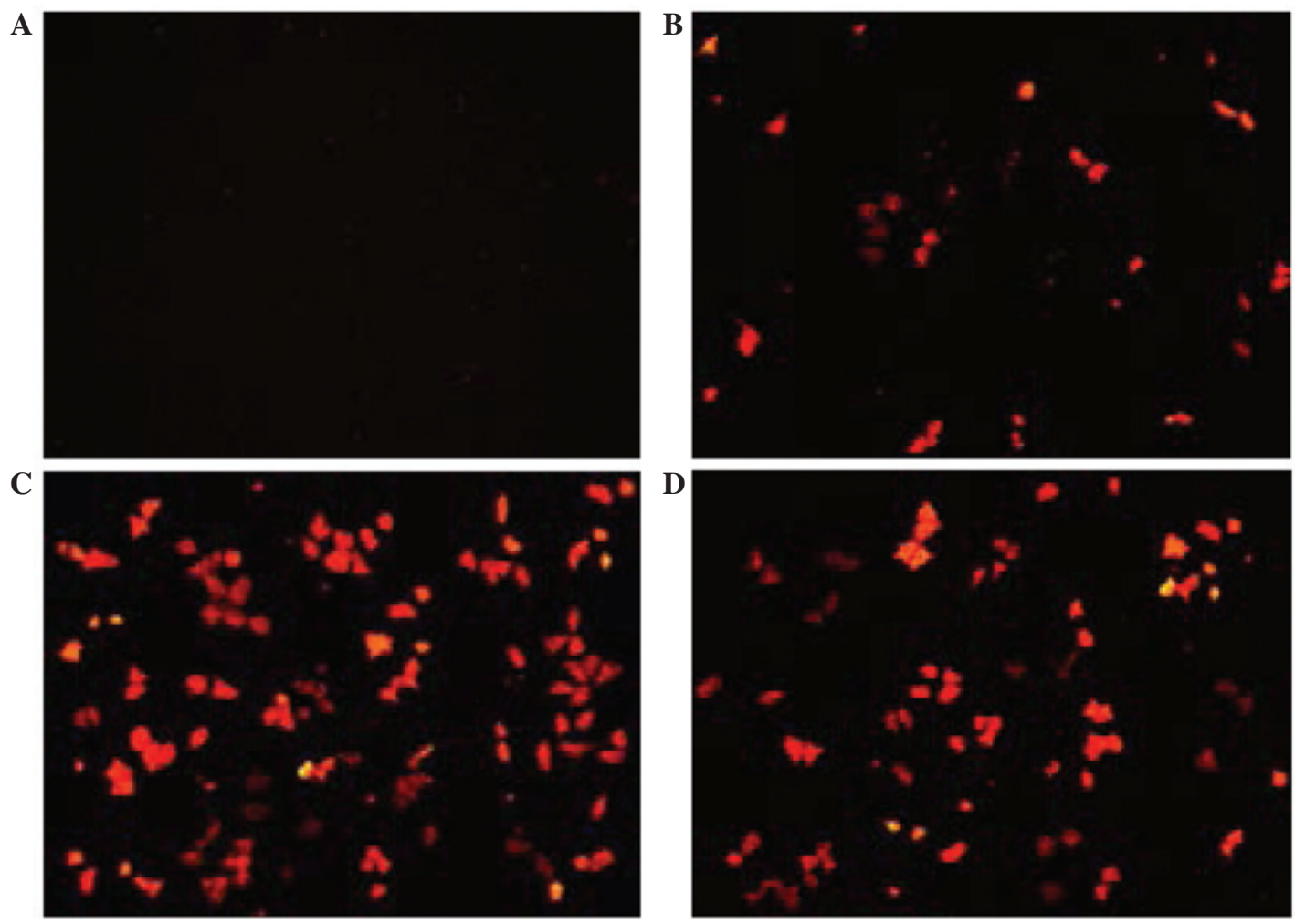

Figure 7. Conditions of the transfection of the malignant melanoma cells with chitosan magnetic nanoparticles and angiopoietin-2-small interfering RNA plasmids mass ratios of (A) 1:1, (B) 1:10, (C) 1:100 and (D) 1:1,000.

reactions to obtain the corresponding $\mathrm{Cq}$ values, which were calculated as follows: $\Delta \mathrm{Ct}=\mathrm{Ang} 2 \mathrm{Ct}$ value - GAPDH Ct value (Table II). According to the formula N1 / N2 $=2^{-\Delta \Delta C t}$, in which $\Delta \Delta \mathrm{Ct}=\Delta \mathrm{Ct}$ experimental group - $\Delta \mathrm{Ct}$ control group, the efficiency of RNAi inhibition of the expression of the Ang2 gene was calculated, and the inhibition rate ratio between the experimental group and the control group was found to be $59.56 \%(\mathrm{P}<0.05)$. The Ang2 plasmid magnetic chitosan nanoparticles should be selected for animal tumor suppression experiments in future studies.

\section{Discussion}

With the increased complexity of basic medical research, gene therapy has become an important component of biological tumor therapy, which is the current focus of biomedical research $(12,13)$. One challenge of gene therapy studies is the choice of a vector system for gene therapy (14).

Gene vectors are usually divided into viral vectors and non-viral vectors. Viral gene vectors include retroviral and adenoviral vectors. Although these vectors demonstrate high transfection efficiency, there is the fundamental issue of toxicity and immune response; thus, non-viral gene vectors have become an extremely important aspect of the pharmaceutical carrier gene $(15,16)$. Chitosan has biodegradable and biocompatible features (17), in addition to the characteristics of low toxicity and cationic polymers; these natural properties of chitosan have caused chitosan to become one of the most promising non-viral gene vectors. In non-viral gene vectors, the intake of gene carrier complexes and gene delivery are also affected by particle sizes (18). Chitosan, as a gene carrier, has previously been a focus of studies (19). Studies have shown that the chitosan molecular weight (20) and the degree of deacetylation (21) have a notable impact on gene transfection. Chitosan nanoparticles are favored for cellular uptake, primarily by endocytosis into cells, and the nanoparticles gradually release nucleic acids by degrading polymer materials. Chitosan nanoparticle vectors are susceptible to covalent and targeted cell ligand modification on the surface, which can result in active targeting of gene transfer. PEG also may be used for surface modification and extending the half-life of the carrier in vivo (22). Therefore, chitosan nanoparticle vectors developed to be gene carriers demonstrate good prospects in gene therapy.

In the present study, the chitosan magnetic nanoparticles were used as a transfection vector for Ang2-siRNA plasmids to induce RNA interference and silence the expression of the Ang2 gene in human malignant melanoma cells. When the mass ratio of chitosan magnetic nanoparticles to Ang2-siRNA plasmids increased between 0.05 and 1.00 , the combination rate of the two demonstrated a rapid increase, while the increase in the binding rate slowed when the amount of chitosan magnetic nanoparticles was increased. At a 1:1 mass ratio of chitosan magnetic nanoparticles and Ang2-siRNA plasmids, the chitosan magnetic nanoparticles bind the majority of the Ang2-siRNA plasmids. Therefore, 4 mass ratios of the Ang2-siRNA plasmid to chitosan magnetic nanoparticles were used in the present study, consisting of 1:1, 1:10, 1:100 and 1:1,000. Following transfection, fluorescence expression of melanoma cells was counted. When the mass ratio of plasmid and chitosan magnetic nanoparticles was $1: 1$, the human malignant melanoma cells showed no red fluorescence protein expression. At a mass ratio of plasmids to magnetic nanoparticles of 1:10, 1:100 or 1:1,000, 
red fluorescent protein was visible. At a mass ratio of 1:100, the emitted red fluorescence was the strongest, as the largest number of human malignant melanoma cells expressed red fluorescent protein, therefore, 1:100 was identified as the best mass ratio and was set as the proportion of plasmids to chitosan magnetic nanoparticles in the experimental and control groups. RT-qPCR was used to determine the expression of the Ang2 gene between the experimental group and the control group, and then the efficiency of the plasmid interference with Ang2 gene expression was analyzed by Ang2-siRNA chitosan magnetic nanoparticles. The results showed that the Ang2-siRNA plasmids and chitosan magnetic nanoparticles may interfere in human malignant melanoma cells in vitro with a higher transfection efficiency and inhibit the expression of the Ang2 gene in malignant melanoma cells.

In summary, the present results revealed that Ang2-siRNA chitosan magnetic nanoparticles could intervene in human malignant melanoma cells in vitro at a high transfection efficiency, and inhibit the expression of the Ang2 gene in malignant melanoma cells, which may lay the foundation and provide experimental evidence for additional in vivo targeting of the angiogenesis and tumor growth of malignant melanoma xenografts in nude mice.

\section{Acknowledgements}

The present study was supported by the Foundation of National Key Clinical Specialty Discipline Construction Program, Scientific Research Foundation of National Health and Family Planning Commission-Joint Research Projects of Fujian Provincial Health and Education (grant no. WKJ-FJ-03) and Projects of Fujian Provincial Natural Science Foundation (grant no. 2012J01125).

\section{References}

1. Parkin DM, Bray F, Ferlay J and Pisani P: Estimating the world cancer burden: Globocan 2000. Int J Cancer 94: 153-156, 2001.

2. Yakovleva ME, Welinder C, Sugiharaa Y, Pawlowskid K, Rezelib M, Wieslandera E, Malme J amd Marko-Varga G: Workflow for large-scale analysis of melanoma tissue samples. EuPA Open Proteomics 8: 78-84, 2015.

3. Essner R: Surgical treatment of malignant melanoma. Surg Clin North Am 83: 109-156, 2003.

4. Oliner J, Min H, Leal J, Yu D, Rao S, You E, Tang X, Kim H, Meyer S, Han SJ, et al: Suppression of angiogenesis and tumor growth by selective inhibition of angiopoietin-2. Cancer Cell 6: 507-516, 2004.

5. Helfrich I, Edler L, Sucker A, Thomas M, Christian S, Schadendorf D and Augustin HG: Angiopoietin-2 levels are associated with disease progression in metastatic malignant melanoma. Clin Cancer Res 15: 1384-1392, 2009.
6. Schlaak M, Kreuzberg N, Mauch C and Kurschat P: Personalized therapy concepts for malignant melanoma. Internist (Berl) 54: 188-193, 2013 (In German).

7. Boguslawska J and Małecki M: siRNA preparations in gene therapy of melanoma. Med Wieku Rozwoj 17: 196-201, 2013.

8. Dolinsek T, Markelc B, Sersa G, Coer A, Stimac M, Lavrencak J, Brozic A, Kranjc S and Cemazar M: Multiple delivery of siRNA against endoglin into murine mammary adenocarcinoma prevents angiogenesis and delays tumor growth. PLoS One 8: e58723, 2013

9. Liu ZL, Wang B, Guo GX, Shan XY, Wang MS, Zhuang FL, Cai CS, Zhang MF and Zhang YD: Construction of recombinant lentiviral vector of siRNA for Ang2 and the effect of the expression of Ang 2 gene in malignant melanoma cells. J Med Mol Biol 8: 494-500, 2011.

10. Wang B, Lin JH, Zhang WQ, Zhang MF, Liu ZL, Shan XY, Wang MS and Zhuang FL: Ang2-siRNA lentivirus interfernce on melanoma xenograft in nude mice. J Med Mol Biol 9: 79-83, 2012.

11. Wang B, Liu Z,Zhang M, San X, Zhang Y,Zhang W and Wang M: Interfering growth of malignant melanoma with Ang2-siRNA. Mol Biol Rep 40: 1463-1471, 2013.

12. Kenjo E, Asai T, Yonenaga N, Ando H, Ishii T, Hatanaka K, Shimizu K, Urita Y, Dewa T, Nango M, et al: Systemic delivery of small interfering RNA by use of targeted polycation liposomes for cancer therapy. Biol Pharm Bull 36: 287-291, 2013.

13. Todorovic V, Sersa G and Cemazar M: Gene electrotransfer of siRNAs against CD146 inhibits migration and invasion of human malignant melanoma cells SK-MEL28. Cancer Gene Ther 20: 208-210, 2013.

14. Stein S, Scholz S, Schwäble J, Sadat MA, Modlich U, Schultze-Strasser S, Diaz M, Chen-Wichmann L, Müller-KullerU, Brendel C, et al: From bench to bedside: Preclinical evaluation of a self-inactivating gammaretroviral vector for the gene therapy of X-linked chronic granulomatous disease. Hum Gene Ther Clin Dev 24: 86-98, 2013.

15. Bonamassa B and Liu D: Nonviral gene transfer as a tool for studying transcription regulation of xenobiotic metabolizing enzymes. Adv Drug Deliv Rev 62: 1250-1256, 2010.

16. O'Rorke S, Keeney M and Pandit A: Non-viral polyplexes: Scaffold mediated delivery for gene therapy. Prog Polym Sci 35: 441-458, 2010.

17. Sionkowska A, Wisniewski M, Skopinska J, Kennedy CJ and Wess TJ: Molecular interactions incollagen and chitosan blends. Biomaterials 25: 795-801, 2004.

18. Pang SW, Park HY, Jang YS, Kim WS and Kim JH: Effects of charge density and particle size of poly (styrene/(dimethylamino)ethyl methacrylate) nanoparticle for gene delivery in 293 cells. Colloids Surf B Biointerfaces 26: 213-222, 2002.

19. Mansouri S, Lavigne P, Corsi K, Benderdour M, Beaumont E and Fernandes JC: Chitosan-DNA nanopartieles as non-viral vectors in gene therapy: Strategies to improve transfection efficacy. Eur J Pharm Biopharm 57: 1-8, 2004.

20. Sato T, Ishii T and Okahata Y: In vitro gene delivery mediated by chitosan. Effect of $\mathrm{pH}$, serum, and molecular mass of chitosan on the transfection efficiency. Biomaterials 22: 2075-2080, 2001.

21. Kiang T, Wen J, Lim HW and Leong KW: The effect of the degree of chitosan deacetylation on the efficiency of gene transfection. Biomaterials 25: 5293-5301, 2004.

22. Mao HQ, Roy K, Troung-Le VL, Janes KA, Lin KY, Wang Y, August JT and Leong KW: Chitosan-DNA nanoparticles as gene carriers: Synthesis, characterization and transfection efficiency. J Control Release 70: 399-421, 2001. 